\title{
SUBMICRON AIRBORNE DUST PARTICLE MONITORING SYSTEM
}

\section{CECILIA ROMAN ${ }^{a}$, MARIUS ROMAN ${ }^{a}$, LUCIAN DORDAI ENIKO KOVACS ${ }^{a, b}$, MARIA-ALEXANDRA HOAGHIA ${ }^{a}$, FERENC PUSKAS ${ }^{\mathrm{c}, *}$}

\begin{abstract}
The harmful effects of airborne dust have been long known, with numerous studies proving the danger it poses to human health. The paper presents a submicron size airborne dust particle monitoring system, built in collaboration by a laboratory equipment manufacturer and a national research and development institute. The system is designed for the automotive industry, the printed circuit board production lines, and the environmental monitoring. It can measure and record data continuously and the loss of the supply voltage does not lead to the loss of the monitoring history. The key element is the particle sensor itself, consisting of a laser diode assembly - CCD area, a suction pump with continuous operation, with constant electronically controlled flow and an electro-optical detector. The system is designed with the following specifications: the applicable particle size: $0.3 \mu \mathrm{m} ; 0.5 \mu \mathrm{m} ; 1.0 \mu \mathrm{m}$; sampling time: $1 . .599 \mathrm{sec}$; programmable (25 sec. by default); average count setting: $2 ; 4 ; 8 ; 16 ; 32 ; 64$; ambient temperature range: operating at $40^{\circ} \mathrm{C}$; power: $220 \mathrm{~V} / 50 \mathrm{~Hz}$; power consumption: max. $25 \mathrm{VA}$; ABS housing, IP rating 54; dimensions ( $\mathrm{L}$ × W x D): 260 x220 x 156 mm; weight: approximately $2.5 \mathrm{~kg}$.
\end{abstract}

Keywords: suspended particulate matter, submicron particle monitoring, air quality, analytical instrumentation

\section{INTRODUCTION}

Particulate matter/suspended particles (PM) or particle pollution is a general term for extremely small particles and liquid droplets existing in the

a INCDO-INOE 2000, Research Institute for Analytical Instrumentation, 67 Donath str., RO400293, Cluj-Napoca, Romania

b University of Agricultural Science and Veterinary Medicine, Faculty of Horticulture, 3-5 Calea Manastur Street, RO-400372, Cluj-Napoca, Romania

c SC ELECTRONIC APRIL, Aparatura Electronica Speciala SRL, 3-5 Louis Pasteur, RO400349, Cluj-Napoca, Romania

*Corresponding author: april_private@yahoo.com 
atmosphere [1]. Exposure to particles pollution represents a public health hazard, because after inhaling them, they can travel deep into the lungs and cause or aggravate heart and lung diseases [2,3].

Particulate matter represents a complex group of pollutants that vary in size, shape, composition and origin. They are often separated into three classes: coarse, fine and ultrafine particles. Coarse particles have a diameter ranging between $10 \mu \mathrm{m}$ and $2.5 \mu \mathrm{m}$ and settle relatively quickly whereas fine (1 to $2.5 \mu \mathrm{m}$ in diameter) and ultrafine $(<1 \mu \mathrm{m}$ in diameter) particles remain in suspension for longer. It must be mentioned that $\mathrm{PM}_{10}$ (coarse) automatically contains $\mathrm{PM}_{2.5}$ (fine) and $\mathrm{PM}_{1.0}$ (ultrafine). In addition, $\mathrm{PM}_{2.5}$ (fine) contains also $\mathrm{PM}_{1.0}$ (ultrafine) and submicron and ultrafine particles (UFPs with diameters below $100 \mathrm{~nm}$ ).

In most countries, both the legislation in force and the regulations define thresholds and require monitoring only $\mathrm{PM}_{10}$ and $\mathrm{PM}_{2.5}$ particles as air pollution factors. Even if the more recent ambient air quality legislations tend to include and consider submicron and ultrafine particles (UFPs) as particulate matter to be monitored with reference to standardized limit values, no regulatory action has been adopted yet $[1,4]$.

Particle size is directly related to the potential to cause adverse effects on human health [5-10]. A serious issue is represented by the particles with an aerodynamic diameter of less than $10 \mu \mathrm{m}$, which pass through the nose and throat and enter the alveoli of the lungs causing inflammation and poisoning, affecting especially people with cardiovascular and respiratory diseases, children, the elderly and asthmatics [11-22]. Children under the age of 15 inhale more air, and consequently more pollutants. They breathe faster than adults and tend to inhale more through the mouth, virtually bypassing the natural filter of the nose. They are especially vulnerable because their lungs are not developed, and the lung tissue that develops in childhood is more sensitive. Dust pollution worsens the symptoms of asthma, coughing, chest pain and difficulty of breathing. Long-term exposure, even to low concentrations of suspended particles can cause cancer and premature death.

In response to the airborne dust particles issue, the European Commission has proposed the Clean Air Policy Package aiming to reduce the impacts of harmful emissions from sources like industry, traffic, energy plants and agriculture (all representing particulate matter generation sources) on the human health and the environment [17].

Airborne particulates are responsible for many problems: environmental (reducing atmospheric visibility) and medical problems (respiratory problems, cancer, and heart attacks). In addition, airborne particulates can cause corrosion of metals and electrical equipment, as well as soiling of textiles and building materials [2]. In response to these identified problems, the United States Environmental Protection Agency (EPA) recognized the need of developing 
techniques and instruments for the continuous measurement of inhalable particulate matter, such as $\mathrm{PM}_{10}$ and $\mathrm{PM}_{2.5}$ and submicron airborne dust particles [1].

There are cases, such as operating rooms, intensive care units (ATI), where it is necessary to monitor the concentration of smaller, submicron particles, because the size of airborne bacteria that cause nosocomial infections are of this order of magnitude. In the case of highly sensitive electronics manufacturing, the presence of the specks of dust can compromise the quality of a product. The study of submicron particles has become of interest in recent years. Rapid and reliable measurement and counting of submicron particles and UFPs are important for the air quality control (regarding the UFPs presence in the air) in fields such as: environmental study, electronic industries, biomedical research, and drug delivery system development.

The electronics manufacturers must ensure the cleanliness of the manufacturing space in order to ensure the sterility and stability of their highly sensitive electronics manufacturing because the smallest speck of dust can lead to contamination or damage to the product that is often impossible to repair. In the electronic industry, air pollution with particulate matter must be constantly monitored by counting the particles for the compliance with the specific environmental requirements. For this reason, the electronic industry i.e. highly sensitive electronics manufacturing, their production halls must be provided with a low level of polluting factors because the activities must be carried out under pre-established safety standards, carefully controlled and the level of contamination must be fully monitored. To fulfil these goals, the air in the production halls is permanently filtered to remove particles and impurities that can damage the activity. The concentration of particles in the air is controlled and the production halls are built and equipped in order to prevent the introduction, generation and retention of particles is minimal, and to control the relevant parameters (temperature, humidity, particulate matter presence, speed) are also controlled [18,19].

ISO 14644-1:2015, Clean rooms and associated controlled environments - Part 1: Classification of air cleanliness by particle concentration, and ISO 14644-2:2015, Clean rooms and associated controlled environments - Part 2: Monitoring to provide evidence of cleanroom performance related to air cleanliness by particle concentration, provide the framework for classifying and monitoring the cleanliness of the air in cleanrooms. Cleanrooms are classified by how clean the air is, according to the number and size of particles permitted per volume of air. For classification purposes there are considered only particle populations having cumulative distributions based on threshold (lower limit) particle sizes ranging from $0.1 \mu \mathrm{m}$ to $5 \mu \mathrm{m}$. Table 1 presents the values of maximum number of particles $/ \mathrm{m}^{3}$ according to each class defined by ISO 14644-1. 
CECILIA ROMAN, MARIUS ROMAN, LUCIAN DORDAI, ENIKO KOVACS, MARIA-ALEXANDRA HOAGHIA, FERENC PUSKAS

Table 1. Maximum number of particles $/ \mathrm{m}^{3}$ and cleanrooms - ISO 14644-a

\begin{tabular}{|c|c|c|c|c|c|c|c|}
\hline \multirow[b]{2}{*}{ Class } & \multicolumn{6}{|c|}{ Maximum number of particles $/ \mathrm{m}^{3}$} & \multirow{2}{*}{$\begin{array}{l}\text { FED STD } \\
209 E \\
\text { equivalent }\end{array}$} \\
\hline & $>=0.1 \mu \mathrm{m}$ & $\begin{array}{c}>=0.2 \\
\mu \mathrm{m}\end{array}$ & $\begin{array}{c}>=0.3 \\
\mu \mathrm{m}\end{array}$ & $>=0.5 \mu \mathrm{m}$ & $>=1 \mu \mathrm{m}$ & $>=5 \mu \mathrm{m}$ & \\
\hline ISO 1 & 10 & 2 & & & & & \\
\hline ISO 2 & 100 & 24 & 10 & 4 & & & \\
\hline ISO 3 & 1,000 & 237 & 102 & 35 & 8 & & Class 1 \\
\hline ISO 4 & 10,000 & 2,370 & 1,020 & 352 & 83 & & Class 10 \\
\hline ISO 5 & 100,000 & 23,700 & 10,200 & 3,520 & 832 & 29 & Class 100 \\
\hline ISO 6 & $1,000,000$ & 237,000 & 102,000 & 35,200 & 8,320 & 293 & Class 1,000 \\
\hline ISO 7 & & & & 352,000 & 83,200 & 2,930 & Class 10,000 \\
\hline ISO 8 & & & & $3,520,000$ & 832,000 & 29,300 & Class 100,000 \\
\hline ISO 9 & & & & $35,200,000$ & $8,320,000$ & 293,000 & Room Air \\
\hline
\end{tabular}

Light scattering (discrete) airborne particle counters (LSAPC) are used for the of airborne particles concentration determination (equal to and greater than the specified sizes, at designated sampling locations), in accordance with ISO 14644-1:2015. When the particle size is smaller than the wavelength of light, the scattering of light energy by particles becomes predominant over reflection or refraction phenomena. There is a nonlinear relationship between the scattered light intensity and the particle size which allows that the particle size to be determined by measuring the intensity of the scattered light.

An LSAPC apparatus is capable to count and classify, i.e. sizing, single airborne particles and to report size data in terms of equivalent optical diameter by using a very bright light source (a laser diode) to illuminate the particles. A photodetector converts the burst of light energy from each particle into a pulse of electrical energy. The height of the signal is measured and is compared with the calibration curve. In this way, the apparatus allows the determination of the particle size, and it is also a counter, the number of pulses determining the quantity allocating the particle numbers into size channels.

In recent years, there is an increased demand for submicron dust monitors, but the offer is limited and prices are elevated. There are many companies that sell such monitors for airborne dust particles, at affordable prices and very good quality, like: INCOTECH, MULTILAB, OPTIMUSAT, AEROQUAL, APEXINST, FLUKE (www.incotech.ro; www.multilab.ro; www.optimusat.ro; www.aeroqual.com; www.apexinst.com, https://www.fluke.com/).

The paper presents a product built at the request of a major manufacturer of electronic circuits for the automotive industry, namely a system for monitoring submicron airborne dust particles (DUMO) (Fig. 1). DUMO, a system that counts the number of particles and measures their size using the light scattering method, represents a real solution for determining airborne particle concentrations, assuring accurate measurements, even for critical locations requiring ISO Class 6. 


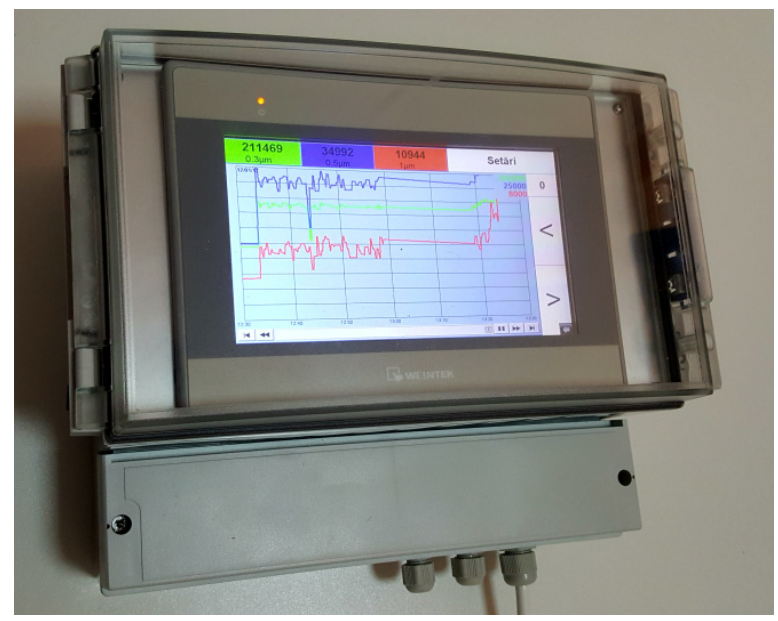

Figure 1. DUMO System for monitoring submicron airborne dust particles (Manufacturer SC ELECTRONIC APRIL, Aparatura Electronica Speciala SRL, Cluj-Napoca, Romania)

\section{RESULTS AND DISCUSSION}

The results obtained from the comparative measurements performed with the DUMO and FLUKE devices are presented in Table 2. The notion of measurement uncertainty is inappropriate, and the counting quality will be discussed from the perspective of counting efficacy, which is the subject of these experiments. The results obtained after the measurement with the FLUKE are considered as a reference and the quality of the measurements performed by DUMO is checked according to the FLUKE results for each point.

Table 2. Number of particles counted/recorded in the production hall

\begin{tabular}{|c|c|c|c|c|c|c|}
\hline \multirow{2}{*}{$\begin{array}{c}\text { Number of } \\
\text { sampling points }\end{array}$} & \multicolumn{3}{|c|}{$\begin{array}{c}\text { Number of particles counted } \\
\boldsymbol{> = 0 . 3} \boldsymbol{\mu m}\end{array}$} & \multicolumn{3}{c|}{$\begin{array}{c}\text { Number of particles counted } \\
\boldsymbol{> = 0 . 5} \boldsymbol{~} \mathbf{m}\end{array}$} \\
\cline { 2 - 7 } & Fluke & DUMO & $\begin{array}{c}\text { Difference } \\
\mathbf{\%}\end{array}$ & Fluke & DUMO & $\begin{array}{c}\text { Difference } \\
\%\end{array}$ \\
\hline 1 & 85789 & 90345 & 5.3 & 4468 & 4255 & 4.8 \\
\hline 2 & 67456 & 71500 & 6.0 & 3689 & 3367 & 8.7 \\
\hline 3 & 47909 & 50123 & 4.6 & 4322 & 4266 & 1.3 \\
\hline 4 & 77566 & 75849 & -2.2 & 6554 & 6177 & 5.8 \\
\hline 5 & 56787 & 60899 & 7.2 & 8777 & 8655 & 1.4 \\
\hline 6 & 42577 & 45788 & 7.5 & 5776 & 5900 & -2.1 \\
\hline 7 & 69994 & 72277 & 3.3 & 5432 & 5444 & -0.2 \\
\hline 8 & 49900 & 52044 & 4.3 & 3978 & 4267 & -7.3 \\
\hline 9 & 48678 & 50398 & 3.5 & 4566 & 4189 & 8.3 \\
\hline 10 & 85655 & 86208 & 0.6 & 3556 & 3899 & -9.6 \\
\hline
\end{tabular}



can be noticed:

By analyzing the results presented in Table 2, the following points

-in all sampling/measuring points, the number of recorded particles values below 102,000 for particles with size $>=0.3 \mu \mathrm{m}$ (max. recorded 85789 with Fluke and 90345 with DUMO in measuring point no. 1: max. registered 8777 with Fluke and 8655 with DUMO. The results show that, in the production hall, the cleaning requirements class 1000 (Table 2) are met;

-in all sampling/measuring points, the number of recorded particles values below 35,200 for particles with size $>=0.5 \mu \mathrm{m}$ (max. recorded 8777 with Fluke and 8655 with DUMO in measuring point no. 5) The results show that, in the production hall, the cleaning requirements class 1000 (Table 2) are met;

-the differences recorded between the two devices are less than $10 \%$, which falls into measurement error of the devices and show/demonstrate the high quality of the built devices, both the FLUKE product and the ELCTRONIC APRIL;

-when counting particles with size $>=0.3 \mu \mathrm{m}$, the values recorded with DUMO are higher by $0.6 \ldots .7 .5 \%$ in $90 \%$ of the cases. Only in sampling point no. 4, the DUMO device recorded a smaller number of particles compared to FLUKE (2.2\%) (Table 2);

-when counting particles with size $>=0.5 \mu \mathrm{m}$, the results are different (Table 2). In $40 \%$ of the cases, the number of particles recorded with DUMO is higher than with FLUKE and, for the remaining $60 \%$, the number of particles is less than of those registered with FLUKE. The most critical case is recorded in sampling point 9 , the difference being $9.6 \%$, but the value is below $10 \%$, i.e. error in the measurement range;

-there is a difference between the values recorded with the Fluke device, which was used as a reference, and the DUMO device due to the wavelengths of the laser diode in the component of the detectors which are different. The scattering on the particles is also affected by the wavelength and the type of component particles of the dust. Because there are various ratios of metallic dust and non-metallic dust at different measurement places, the scattering on the two wavelengths differs, resulting in seemingly uncorrelated data, i.e. "heteroskedastic behavior";

-for the two sets of data, a statistic paired t-test was applied and the results showed that for the values recorded in the case of particles with dimensions $>=0.3$ microns, the difference between the two data sets, FLUKE and DUMO, is statistically significant $(p<0.05)$; for the values recorded for particles with dimensions $>=0.5$ microns, the difference between the two data sets, FLUKE and DUMO, is not significant, $p=0.421,(p>0.05)$. 


\section{CONCLUSIONS}

Particulate matter, consisting of a mixture of solid and liquid particles suspended in the air, is of particular importance in the electronic industry, where their continuous monitoring is needed in order to maintain the conditions in the cleanrooms. A system for monitoring submicron airborne dust particles, DUMO, was built for the production plants in the electronic industry with an ISO 1,000 cleaning class. DUMO can be used for: cleanrooms monitoring, indoor air quality investigation and particles size distribution monitoring.

The tested and verified system is an easy-to-use instrument, meets the requirements formulated by ISO 14644-1 and has specifications comparable to a FLUKE device, one of the best on the market, all these recommending DUMO for mass production and marketing.

\section{EXPERIMENTAL SECTION}

System construction. At the request of a major electronic circuits manufacturer for the automotive industry, a system was designed and built to verify and monitor the air quality in a production hall with ISO 1,000 cleaning class. The beneficiary requested to monitor only the size and not the composition of the airborne particles. Two size categories of submicron dust were of particular interest: 0.3 and $0.5 \mu \mathrm{m}$, since these are the size ranges monitored in cleanrooms at his production plant (electronic industry). After studying the specialized literature, it was decided to build a particle counter determining airborne particle concentrations (DUMO), device that meets all the requirements specified by ISO 14644-1:2015, taking into account that it also specifies the standard method of testing to determine the cleanliness class, including the selection of sampling locations. DUMO, a light scattering (discrete) airborne particle counter, was designed for: high accuracy, on-screen data presentation, the ability to perform more experiments rapidly and the ability to access and analyze data anytime. DUMO is an LSAPC and the measurement principle is based on the detection of light scattered by a particle which passes through an incident light beam. The particle size is determined from the intensity of scattered light and the number of light pulses scattered by individual particles. DUMO can quantify the number of particles as particle number concentration per volume of air in different size range categories.

The key element of the DUMO is the particle sensor itself, consisting of a laser diode assembly - CCD area, suction pump with continuous operation with electronically controlled constant, and the electro-optical detector. The 
DUMO operation is based on the scattering of a laser beam on air samples taken from the environment, with illumination at 90 degrees with a semiconductor laser diode. The laser beam is scattered on the dust particles and reaches the CCD area, where the concentration and size of the particles can be determined using the electrical signals received. The measurement principle is illustrated in Fig. 2.

The ZN-PD03 sensor, air particle sensor for in-line measurement produced by Omron Corporation, was used due to the unique advantages it offers [20]:

- robust, compact construction, with magnetic levitation suction pump

- coarse dust filter, for particles larger than 1 micron

- calibrated from the factory for applicable particle size 0.3-0.5-1.0 microns

- $\quad$ providing additional modules for signal processing

- $\quad$ simple wiring

- $\quad$ very good resistance to vibrations: 10 to $55 \mathrm{~Hz}, 0.7-\mathrm{mm}$ double amplitude 80 min each in $\mathrm{X}, \mathrm{Y}$, and $\mathrm{Z}$ directions

- $\quad$ very good resistance to shocks: $150 \mathrm{~m} / \mathrm{s}^{2}$ three times each in six directions (up/down, left/right, forward/backward

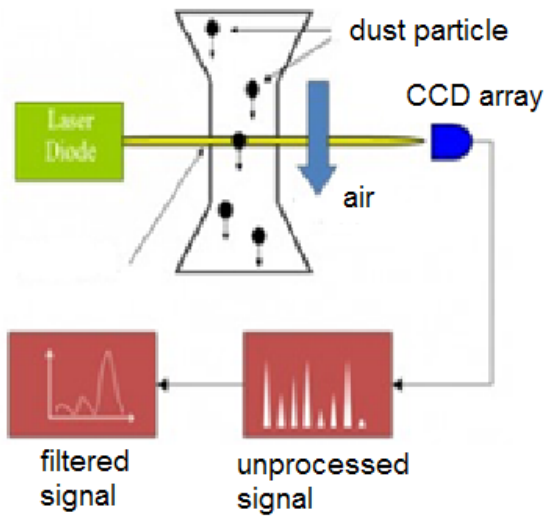

Figure 2. DUMO measurement principle

The sensor connects to the ZN-PDA11 type amplification module (Omron Corporation), which processes the analog signals sent by the sensor, and displays the measured values from a miniaturized numerical display [21]. The measurement conditions are also established on this module, such as: 
- $\quad$ sampling time

- $\quad$ number of mediated samples

- $\quad$ the unit of measurement in which the values will be indicated

- $\quad$ scaling the obtained values, offset correction and amplification

The amplifier module forwards digital signals to another Omron module, the ZN-SFW11, the serial transmission module, which processes and transforms information for the standard RS232 serial interface. The block diagram of the assembly can be seen in Fig. 3.

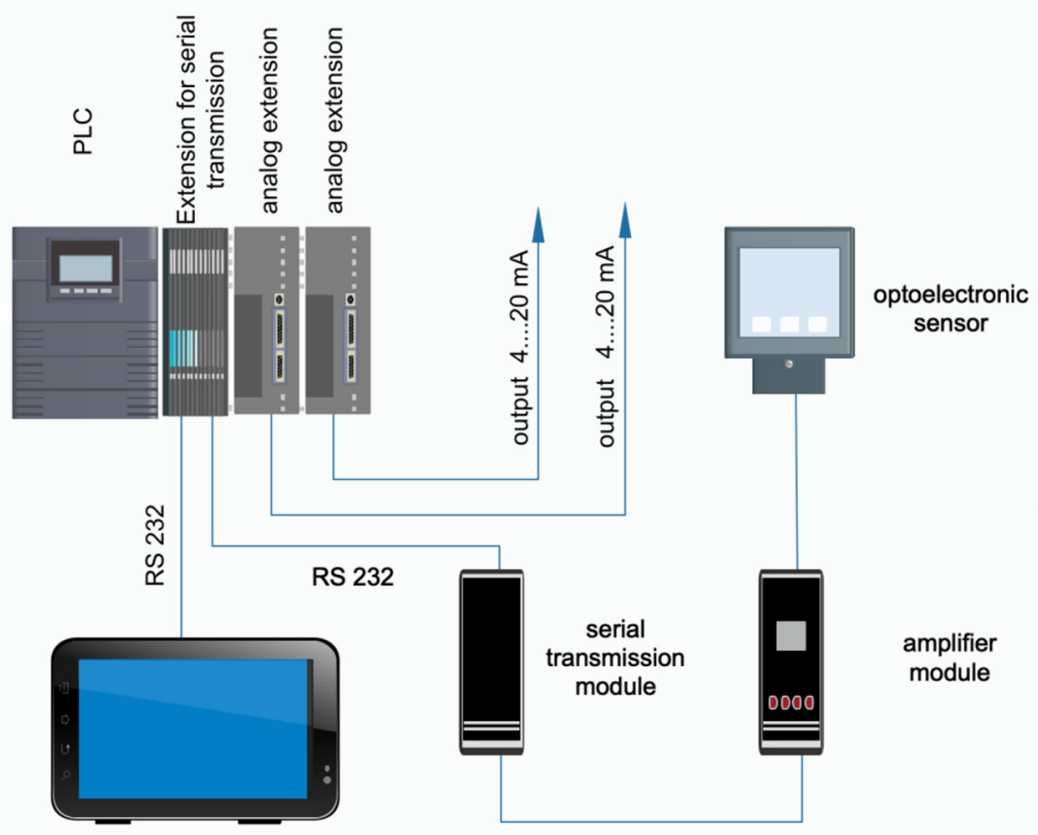

Figure 3. Block diagram of the DUMO system

The costumer requested that the results be displayed graphically, the 8-hour trend at the device installation point, the 30-day measurement history be downloadable to a USB memory, readable in Excel, and the measured values will be transmitted remotely as a unified signal $4 \ldots 20 \mathrm{~mA}$. For this purpose, a computing unit was built around a DirectLogic25 programmable controller with serial communication module extensions and two $4 . .20 \mathrm{~mA}$ analog output modules. Attached to this computing system is a 7" color touchscreen display that acts as a human-machine interface. The communication between the PLC and the display takes place through the RS232 serial interface. 
Experiments performed. The experiments aimed at verifying the accuracy of measuring submicron particles. The experiments were performed in the production hall of the customer for whom this system was built. The measurements were conducted in the PCB manufacturing and implantation hall of the beneficiary at the points identified by his representative.

The ISO 14644 standard was used for the determination of measurement points, their positioning in the production hall, number and duration of sampling at each point, calculation of the average concentration value for each measurement point, total average, standard deviation of the average value for each measurement/sampling point [18]. The sampling locations within each segment were chosen to be "representative of the characteristics" of each section of the production hall, taking into account that ISO14644-2:2015 Sample Point Placement ISO 14644-1/2:2015 is also a beneficial tool to use in achieving mature cleanroom environmental control. The aim of the experiments was to identify critical areas, if they exist and to understand the contamination sources and their impact on the activity in the production hall.

To evaluate the measurement accuracy, 10 systems were placed in the customer's production plant, at critical points for air quality (selected according to ISO 14644), and the values indicated by DUMO in parallel with a Fluke 985 laboratory particle measuring device for sizes between 0.3 and 0.5 microns were recorded. At each point, 8 measurements were performed, and the averages were recorded, which were then analyzed and interpreted.

\section{DUMO Specification and Key features:}

- particle size rage: $0,3 \mu \mathrm{m} ; 0,5 \mu \mathrm{m} ; 1.0 \mu \mathrm{m}$

- $\quad$ sampling time: $1 \ldots . . .599 \mathrm{sec}$

- $\quad$ programmable (25 sec. by default)

- $\quad$ average count setting: $2 ; 4 ; 8 ; 16 ; 32 ; 64$

- operating temperature: $0 \ldots \ldots . .40^{\circ} \mathrm{C}$

- power: $220 \mathrm{~V} / 50 \mathrm{~Hz}$

- power consumption: max. $25 \mathrm{VA}$

- housing: ABS

- IP rating: IP 54

- dimensions: $260 \times 220 \times 156 \mathrm{~mm}$

- weight: approx. $2,5 \mathrm{~kg}$

- channels: 6; simultaneously measures and displays 6 channels of particle size, ambient temperature and humidity

- the loss of the supply voltage does not lead to the loss of the measurement history. 


\section{ACKNOWLEDGMENTS}

This work was supported by a grant of the Romanian Ministry of Research and Innovation, CCCDI -UEFISCDI, contract number 65PTE/2020, within PNCDI III.

\section{REFERENCES}

1. ${ }^{* * *}$ https://www.epa.gov/pm-pollution, online source accessed in 08 January 2021.

2. C.A. Pope, Inhal. Toxicol., 2007, 19, 33-38. doi.org/10.1080/08958370701492961

3. C.A. Pope, D.W. Dockery, J. Air Waste Manag. Assoc., 2006, 56, 709-742. doi.org/10.1080/10473289.2006.10464485

4. C.A. Pope, R.T. Burnett, M.C. Turner, Environ. Health Perspect., 2011, 119, 1616-1621. doi: 10.1289/ehp.1103639

5. R. Zhang, G. Wang, S. Guo., M.L. Zamora, Q. Ying, Y. Lin, W. Wang, M. Hu, Y. Wang, Chem. Rev., 2015, 115, 3803-3855. doi: 10.1021/acs.chemrev.5b00067

6. P. Kumar, A. Robins, S. Vardoulakis, R. Britter, Atmos. Environ, 2010, 44, 5035-5052. doi:10.1016/j.atmosenv.2010.08.016

7. P. Paasonen, M. Peltola, J. Kontkanen, H. Junninen, V.M. Kerminen, M. Kulmala, Atmos. Chem. Phys., 2018, 18, 12085-12103. doi: 10.5194/acp-18$12085-2018$

8. M. Manigrasso, M. Vitali, C. Protano, P. Avino, Environ. Int., 2018, 118, 134-145.

9. C. Nguyen, L. Q. Li, C.A. Sen, E. Ronquillo, Y.F. Zhu, Atmos. Environ., 2019, 211, 159-169.

10. M.R. Heal, P. Kumar, R. Harrison, Chem. Soc., 2012, 41, 6606. https://doi.org/10.1039/c2cs35076a

11. ${ }^{* * *}$ US - EPA, National Ambient Air Quality Standards for Particulate Matter; Final Rule. Federal Register 78, 2013,10, 3086-3287.

12. ${ }^{* * *}$ WHO, Review of evidence on health aspects of air pollution - REVIHAAP Project. Copenhagen, Denmark, 2013, https://www.euro.who.int/_data/assets

13. *** Joint Research Centre. Particle Measurement Programme (PMP): Interlaboratory correlation exercise with Condensation Particle Counters (CPCs). 2018, (Publications Office of the European Union).

14. B. Giechaskiel, B. Combust. Engines, 2018, 174, 3-16.

15. ${ }^{* * *}$ https://www.health.ny.gov/environmental/indoors/air/pmq_a.htm, online source accessed in 08 January 2021.

16. H.-S. Kwon, M. H. Ryu, C. Carlsten, Experim. Mol. Med., 2020, 52, 318-328.

17. ${ }^{* * *}$ https://www.consilium.europa.eu/en/policies/clean-air/

18. ${ }^{* * *}$ ISO 14644:2019, Cleanrooms and associated controlled environments, www.iso.org/iso/foreword.htm 
CECILIA ROMAN, MARIUS ROMAN, LUCIAN DORDAI, ENIKO KOVACS, MARIA-ALEXANDRA HOAGHIA, FERENC PUSKAS

19. ${ }^{* * *}$ ISO 14698-1:2003, Cleanrooms and associated controlled environments Biocontamination control - Part 1: General principles and methods, https://www.iso.org/obp/ui/\#iso:std:iso:14698:-1:ed-1:v1:en

20. ${ }^{* * *}$ Omron Corporation-Instruction Sheet for Zn-PDA air particle sensor, https://www.omron.com/global/en/

21. ${ }^{* * *}$ Omron Corporation-Instruction Sheet for air particle amplifier unit, https://www.omron.com/global/en/ 